\title{
Entrepreneurship, Governance and Ethics
}

\section{Robert Cressy \\ Douglas Cumming Christine Mallin}

When Integrity declines, workability declines. When workability declines the available opportunity for performance declines. Thus, Integrity is an important factor of production.

Michael Jensen, Jesse Isidor Straus Professor of Business Administration, Emeritus, Harvard Business School, Keynote Remarks at the Conference on Law, Ethics and Finance at York University Schulich School of Business, September 2010.

A joint special issue conference on Law, Ethics and Finance was held at the York University Schulich School of Business, 16-18 September, 2010. The event was sponsored by the Schulich School of Business and the CFA Institute, with the cooperation of two leading academic journals, the Journal of Business Ethics and the European Journal of Finance. Amongst over 50 papers submitted for each of the two special issues, 19 were invited for presentation at the conference. The authors represented 9 countries: Australia, Belgium, China, France, Italy, the Netherlands, Spain, the UK and the US. Michael Jensen, Jesse Isidor Straus Professor of Business Administration, Emeritus, Harvard Business School, gave a keynote presentation on Financial Market Integrity. The authors at the conference represented a variety of perspectives from ethics, entrepreneurship, governance, economics, law and finance, thereby enabling interesting interdisciplinary discussion and debate.

The event began on 16 September 2010 with a Panel Discussion on 'Financial Market Integrity: Paths Forward,' which included Michael Jensen, Jesse Isidor Straus Professor of Business Administration, Emeritus, Harvard Business School, Robert Bertram, CFA, former Executive President of the Ontario Teachers' Pension, Jeff Diermeier, CFA, former President and CEO of the CFA Institute, Susan Wolburgh Jenah, CEO of the Investment Industry Regulatory Organisation of Canada. The panel members discussed current topics on ethics, market integrity and the role of regulation in facilitating market integrity. The panel made particular note of the lack of a regulatory structure in Canada for facilitating financial market integrity, and this deficiency increases the cost of capital for Canadian firms. The items discussed highlighted the intersection of law, ethics, governance, entrepreneurship and finance, which provided a strong kick-start to the academic sessions on 17 and 18 September 2010.

In the keynote address on 17 September 2010, Professor Jensen distinguished integrity from ethics, morality and legality, and highlighted the role of integrity in enhancing organisational efficiency. Legality refers to the system of laws and regulations of right and wrong behaviour of a person, group, or entity that are enforceable only by the state through a policing a judicial process with penalties. Ethics refers to the agreed on standards of what is desirable and undesirable, of right and wrong conduct or behaviour of a person, group or entity. Morality refers to the societal generally acceptable standards of what is desirable or undesirable, and right and wrong conduct of people, groups or entities. Integrity encompasses legality, ethics and morality. Key aspects of integrity include honouring one's word, telling people when you are not able to honour your work as soon as you become aware you are not able to fulfil your promise, and taking steps to fix the mess that is created when you do not honour one's word. Professor Jensen gave examples of improvements in organisation efficiency associated after implementing a code of integrity. One example was about the organisation that he 
co-founded, the Social Science Research Network, which experienced a more than 100\% efficiency improvement after implementing a code of integrity.

The best papers submitted for consideration for the Journal of Business Ethics were picked for inclusion at the conference. Some of the conference papers were not accepted for the special issue. The best papers that made it into the special issue included the following ten papers that appear in this issue. The first three papers ('Deal Structuring in Philanthropic Venture Capital Investments,' 'The Role of Law, Corruption and Culture in Investment Fund Manager Fees,' and 'Legal Protection, Corruption and Private Equity Returns in Asia') deal with the issues of law, ethics and finance of entrepreneurial start-ups and their investors. The fourth and fifth papers ('Exploring the Impact of Legal Systems and Financial Structure on Corporate Responsibility,' and 'The UK Alternative Investment Market Ethical Dimensions') pertain to differences in ethics across different stock exchanges and legal systems. The sixth and seventh papers ('Corporate Scandals and Capital Structure,' and 'Corporate Fraud and Managers' Behaviour: Evidence from the Press') consider the effect of corruption on managerial decisions. The eighth, ninth and tenth papers ('Player and Referee Roles Held Jointly: The Effect of State Ownership on China's Regulatory Enforcement Against Fraud,' 'Reactivity and Passivity after Enforcement Actions: Better Late than Never,' and 'Chinese Management Buyouts and Board Transformation') consider issues of law, ethics and finance in China.

In particular, Luisa Alemany and Mariarosa Scarlata, in 'Deal Structuring in Philanthropic Venture Capital Investments,' consider a new issue that has received scant academic attention: philanthropic venture capital. Philanthropic venture capital considers financing entrepreneurial ventures with the aim of maximising the social return on the investment. Alemany and Scarlata examine the deal structuring phase of philanthropic venture capital investments in terms of valuation, security design and contractual covenants. The authors provide empirical evidence from Europe and the United States. The data examined highlight that the nondistribution constraint holding for non-profit social enterprises is an effective tool to align the interests of both investor and investee. As a result, philanthropic investors are more like stewards than principals. It is noteworthy that the same venture capitalists structure their non-philanthropic investments in the same way as traditional venture capitalists with consideration to investment moral hazard and other risks.

Sofia Johan and Dorra Najar, in 'The Role of Law, Corruption and Culture in Investment Fund Manager Fees,' examine an international sample of venture capital and private equity funds to assess the role of law, corruption and culture in setting fund manager fees. The authors provide recent evidence from news and other media that fee setting in venture capital and private equity organisations is rife with issues of corruption and legal scrutiny. By examining an international sample of fees, the authors are able to compare various determinants of fees, and show that the data examined strongly indicate that corruption, culture and legal settings are much more significant in determining fees than fund manager characteristics and/or market conditions. In particular, the authors show that in countries with better legal conditions, fixed fees are lower, carried interest fees are higher, clawbacks are less likely, and share distributions are more likely. Countries with lower levels of corruption have lower fixed fees and higher performance fees, and are less likely to have clawbacks and cash-only distributions. Furthermore, they show that Hofstede's measure of power distance is negatively related to fixed fees and the use of cashonly distributions, but positively related to performance fees and clawbacks.

Douglas Cumming, Grant Fleming, Sofia Johan and Mai Ta, in 'Legal Protection, Corruption and Private Equity Returns in Asia' examine the impact of country differences in corruption and law quality on private equity returns. The authors utilize a unique data set comprising over 750 returns to private equity transactions across 20 developing and developed countries in Asia. The authors find that the quality of legal system (including legal protections) is positively related to returns. The main explanation is that inefficient legal protections negatively impact transaction structures and economic certainty when exiting investments. However, the authors also find that private equity returns are higher in countries with higher levels of corruption. This finding is consistent with the view that private equity managers bring about organisational change to alleviate the costs of corruption. The authors 
show that their findings are robust to inclusion of controls for Hofstede cultural variables, economic conditions and transaction specific characteristics, as well as consideration of econometric sample selection methods.

Celine Gainet, in 'Exploring the Impact of Legal Systems and Financial Structure on Corporate Responsibility,' investigates how diverse European legal systems and financial structures influence corporate social and environmental responsibility. Gainet tests hypotheses that integrate legal systems and financial structures related to environmental responsibility with Innovest data gathered between across 16 countries and over 600 companies. The data examined show legal systems influence corporate responsibility in both social and environmental spheres. Corporations are more likely to act in environmentally responsible ways when there are strong and well-enforced state regulations in place to ensure such behaviour. Gainet also finds that for large companies, which are more visible than small ones, society expects them to behave in a more socially and environmentally responsible manner regardless of their financial performance or available cash. Also, the data examined support the hypothesis that capital structure significantly influences corporate responsibility insofar as companies with comparatively less debt are more likely commit to social and environmental activities.

Chris Mallin and Kean Ow-Yong, in "The UK Alternative Investment Market - Ethical Dimensions,' examine the development of the UK Alternative Investment Market (AIM) since it was launched in 1995 and its growth with over 1200 companies currently listed. The authors highlight potential pitfalls that the lighter touch regulation on AIM which in turn may give rise to corporate governance and ethical issues. The authors examine the central role of the nominated advisor (NOMAD) and the potential governance and ethical implications. Further, the authors discuss some of the concerns that AIM participants have about the market, including recent scandals on AIM. The authors discuss the implications of their findings for academics, investors and policymakers alike.

Stefano Bonini and Diana Boraschi, in 'Corporate Scandals and Capital Structure,' analyse whether companies involved in a security class action suit (SCAS) exhibit differential capital structure deci- sions. Also, the authors consider whether the information revealed by a corporate scandal affects the security issuances and stock prices of industry peers. The data examined show that before a SCAS is filed companies involved in a scandal issue greater amounts in security offerings. Further, equity mispricing increases the benefits associated with the use of equity financing. Following the SCAS filing, however, companies exhibit a decreasing amount of total external finance raised. Industry peers are similarly affected, due to contagion. The authors further show that corporate scandals have significant negative effects on stock prices and bond ratings.

Jeffrey Cohen, Yuan Ding, Cedric Lesage and Herve Stolowy, in 'Corporate Fraud and Managers' Behaviour: Evidence from the Press,' examine press articles covering 39 corporate fraud cases over 19922005 to study managers' behaviour in the commitment of the fraud. This study integrates the fraud triangle (FT) and the theory of planned behaviour (TPB). The data examined suggest that personality traits appear to be a major fraud risk factor. The analysis was further validated through a quantitative analysis of key words associated with the attitudes/ rationalizations component of the integrated theory. These words were found to be used in fraud firms as opposed to a sample of control firms. The findings have significant policy implications. For instance, auditors should evaluate the ethics of management through the components of the theory of planned behaviour: the assessment of attitude, subjective norms, perceived behavioural control and moral obligation. Professional standards that are related to fraud detection should have a stronger emphasis on managers' behaviour that may be associated with a lack of ethics.

Wenxuan Hou and Geoff Moore, in 'Player and Referee Roles Held Jointly: The Effect of State Ownership on China's Regulatory Enforcement Against Fraud,' examine the impact of the prevailing state ownership in the Chinese stock market on fraud. In particular, the authors consider the effect on corporate governance and the financial regulatory system, respectively, as the internal and external monitoring mechanisms to deter corporate fraud and protect investors. The data examined show that the retained state ownership in privatised firms increases the incidence of regulatory enforcements against fraud. Also, the authors show that a new regulation 
'Solutions for Listed Firm Checks,' which was promulgated in March 2001, has empowered the Regulatory Commission to increase the severity of punishment associated with regulatory infringements against fraud. The data examined show this improvement in the regulatory environment and investor protection has helped the Chinese stock.

Shujun Ding, Chunxin Jia, Yianshun Li and Zhenyu Wu, in 'Reactivity and Passivity after Enforcement Actions: Better Late than Never,' examine the dynamics between enforcement actions and the responses from both the board of directors and supervisory boards amid China's governance reform. Rather than examining determinants of fraudulent activities, the authors investigate, after enforcement actions are imposed, if the board of directors and supervisory boards react differently, and whether their different reactions play a role in preventing future occurrences of frauds. The data examined shows that both boards react to enforcement actions, but only the responses from the board of directors help to curb future enforcements under certain circumstances. The supervisory board fails to play any role in preventing future enforcements. The findings have important policy implications for rule setting associated with ethical conduct and differing levels of boards of directors.

Finally, Yao Li, Mike Wright, Louise Scholes, in 'Chinese Management Buyouts and Board Transformation,' assess the extent to which Chinese management buyouts (MBOs) of listed corporations enable a balance to be achieved between facilitating growth and supporting the interests of minority shareholders other than the buyout organisation. The authors compare MBOs with non-MBOs and examine the extent to which boards of directors are changed to bring in executive and outside directors with the skills to grow as well as restructure a business. The authors also examine the extent to which outside directors become involved in actions to develop the business rather than actions related to fostering the interests of all shareholders. The authors find little evidence that outside board members have the skills to add value to the MBO firms. Boards appear to focus mainly on related party transactions with limited attention to growth strategies. Outside directors do not seem to openly disagree with incumbent managers on the disclosure of their actions.

Overall, the collection of ten papers in this special issue highlights with empirical data the strong interplay on ethics in organisational efficiency and entrepreneurial activity, and the role of legal settings and governance in facilitating ethical standards. We hope these papers encourage future scholars to continue to investigate the role of law and corporate governance in mitigating corruption and facilitating integrity in management, entrepreneurship and finance.

\section{Acknowledgments}

We owe thanks to the seminar participants at the Conference on Law, Ethics and Finance at York University Schulich School of Business, September 2010, and to the referees for their helpful comments.

Robert Cressy and Christine Mallin Birmingham Business School, University of Birmingham, Birmingham, U.K. E-mail:r.cressy@bham.ac.uk

Christine Mallin E-mail:c.a.mallin@bham.ac.uk

Douglas Cumming Schulich School of Business, York University, Toronto, ON M3J 1P3, Canada E-mail:dcumming@schulich.yorku.ca 